\title{
PERFIL DE UTILIZAÇÃO DOS SISTEMAS DE INFORMAÇÃO POR EMPREENDEDORES DO MUNICÍPIO DE PARAUAPEBAS, ESTADO DO PARÁ
}

\author{
PROFILE OF USE OF INFORMATION SYSTEMS BY ENTREPRENEURS OF \\ MUNICIPALITY OF PARAUAPEBAS, PARA STATE
}
Recebido em 02.03.2019 Aprovado em 10.12.2019
Avaliado pelo sistema double blind review
DOI: https://doi.org/10.32888/cge.v7i3.28188

\author{
Daniel Barbosa Cabral \\ danicabral@msn.com \\ Universidade Federal Rural da Amazônia - Parauapebas / Pará, Brasil \\ Alisson de Oliveira Veras \\ alisson.doajg@hotmail.com \\ Universidade Federal Rural da Amazônia - Parauapebas / Pará, Brasil \\ Josué Wilkerson Costa de Sousa \\ josuemgm@hotmail.com \\ Universidade Federal Rural da Amazônia - Parauapebas / Pará, Brasil \\ Jéssica Patrícia Lopes \\ jessicalopess2@,outlook.com \\ Universidade Federal Rural da Amazônia - Parauapebas/Pará, Brasil
}

\section{Resumo}

Este artigo tem como objetivo identificar o perfil de utilização dos sistemas de informação por empreendedores do munícipio de Parauapebas, estado do Pará. Nos procedimentos metodológicos, a pesquisa descritiva contou com a participação de 60 empreendedores da cidade que responderam a um questionário estruturado com questões sobre o perfil de utilização dos sistemas de informação. Os dados coletados foram analisados e apresentados em dois blocos. O primeiro bloco descreve u as características das empresas participantes e o segundo identificou o perfil de utilização dos sistemas de informação. Os resultados indicaram que os sistemas de informação são considerados essenciais pelos empreendedores para auxiliarna gestão dos negócios. Conclui-se que os sistemas de informação são responsáveis por trazer maior controle das atividades e dos recursos empregados, dando aos empreendedores possibilidades de melhorar a gestão dos seus negócios.

Palavras-chave: Sistemas de Informação. Empreendedorismo. Amazônia. Parauapebas. Pará.

\begin{abstract}
This article aims to identify the profile of the use of information systems by entrepreneurs of the municipality of Parauapebas, state of Pará. In the methodological procedures, the descriptive research was attended by 60 entrepreneurs from the city who answered a questionnaire structured with questions about the profile of the use of information systems. The collected data were analyzed and presented in two blocks. The first block described the characteristics of the participating companies and the second identified the profile of the use of information systems. The results indicated that information systems are considered essential by the entrepreneurs to assist in the management of the business. It is concluded that information systems are responsible for bringing greater control of the activities and resources employed, giving entrepreneurs possibilities to improve the management of their business.
\end{abstract}

Keywords: Entrepreneurship. Information System. Amazon. Parauapebas. Pará. 


\section{Introdução}

O conceito de empreendedorismo tem sido muito difundido no Brasil, nos últimos anos, intensificando-se no final da década de 1990, mas cujo início, como marco da consolidação do tema e de sua relevância para o país, ocorreu a partir de 2000 (DORNELAS, 2018). Segundo a Global Entrepreneurship Monitor [GEM], organização internacional que realiza pesquisas sobre o empreendedorismo em 54 países, o Brasil ocupa a 20a posição do Ranking de Espírito Empreendedor em 2018. O índice é baseado em uma combinação de três questões relacionados à conscientização empreendedora, percepção de oportunidade e eficácia empreendedora e são comparáveis entre os países participantes do projeto.

Em mercados globais cada vez mais dinâmico e que gera inúmeras informações cada vez mais complexas, pode-se afirmar que o gerenciamento das informações é essencial para o sucesso das organizações. A informação é um dos mais importantes patrimônios que qualquer organização tem à sua disposição e tudo que uma organização faz, envolve o uso da informação de algum modo (LAUDON; LAUDON, 2005). Para algumas organizações, a informação é considerada um ativo estratégico e valioso (BALTZAN; PHILLIPS, 2012).

O propósito básico da informação é habilitar a empresa a alcançar seus objetivos pelo uso efici ente dos recursos disponíveis, portanto, as informações podem decidir o futuro da organização (BAZZOTTI; GARCIA, 2006). Considera-se fundamental, para gerir um negócio bem-sucedido, a compreensão do impacto direto que a gestão da informação tem sobre o res ultado de uma organização (BALTZAN; PHILLIPS, 2012). A utilização dos sistemas de informação como ferramentas de apoio ao empreendedor na execução do seu negócio, surgiu como uma necessidade primordial.

A gestão dos sistemas de informação tornou-se essencial em organizações de diversos segmentos e tamanhos, tanto públicas como privadas. A localização das organizações pode ter características distintas para o uso dos sistemas de informação, como por exemplo, as organizações localizadas em cidades brasileiras com economia pujante, competividade elevada, isoladas de grandes centros urbanos tradicionais ou dependentes economicamente de poucas atividades de negócios.

O Ministério de Industria, Comércio Exterior e Serviços divulgou no balanço de 2016 a lista dos maiores municípios exportados em valores do Brasil e o munícipio de Parauapebas, no estado do Pará, destacou-se com primeira posição no ranking nacional com US \$ 7,62 bilhões, superando as maiores metrópoles brasileiras, as cidades do Rio de Janeiro com US \$ 7,49 bilhões em segundo e de São Paulo em terceiro com US $\$ 7,32$ bilhões.

A cidade de Parauapebas está localizada na região amazônica brasileira e destaca-se por ter em seu território a maior jazida de minério de ferro a céu aberto do mundo, na região da Serra de Carajás (VALE, 2018). Com um PIB - Produto Interno Bruto de aproximadamente R $\$ 11,2$ bilhões, sendo o segundo maior do estado do Pará e inferior apenas cidade de Belém, o munícipio de Parauapebas concentra elevada participação da atividade da indústria, principalmente a de mineração, tendo o VAB - Valor Adicionado Bruto da Industria equivalente a aproximadamente 66\% do seu PIB (Instituto Brasileiro de Geografia e Estatística, 2015).

Segundo o IBPT - Instituto Brasileiro de Planejamento e Tributação (2018), através do projeto intitula do Empresômetro que realiza um censo das empresas e entidades públicas e privadas atuantes no Brasil e contabiliza em tempo real, existem 15.088 empresas abertas em Parauapebas, colocando o munícipio na quinta posição no estado do Pará.

Diante deste cenário econômico na cidade de Parauapebas, com valores que são destaques no Brasil, este trabalho propõe-se a identificar o perfil de utilização dos sistemas de informação por empreendedores do município de Parauapebas, estado do Pará. 
Além desta seção de introdução, este artigo possui mais quatro seções. A parte teórica deste trabalho é a segunda seção, foi elaborada através de extensa pesquisa bibliográfica, e está dividida em duas partes. A primeira parte descreve as definições de empreendedorismo e empreendedor. A segunda parte descreve os conceitos de informação e sistemas de informação. Os procedimentos metodológicos estão descritos na seção seguinte. A quarta seção apresenta os resultados da pesquisa de campo e análise dos dados coletados. Por fim, na quinta seção são feitas as considerações finais.

\section{Empreendedorismo}

A palavra empreendedorismo foi originada da tradução da expressão entrepreneurship da língua inglesa que, por sua vez, é composta da palavra francesa entrepreneur e do sufixo inglês ship (BAGGIO; BAGGIO, 2015). O empreendedorismo pode ser apresentado como algo tão importante para o século XXI, como a Revolução Industrial foi para o século XX (TIMMONS, 1994). O empreendedorismo é o envolvimento de pessoas e processos que, em conjunto, levamà transformação de ideias em oportunidades, e a perfeita implementação destas oportunidades leva à criação de negócios de sucesso (HISRICH, PETERS; SHEPHDERD, 2014).

A ênfase em empreendedorismo surge muito mais como consequência das mudanças tecnológicas e sua rapidez, e não apenas como mais um modismo (DORNELAS, 2018). Pode-se dizer que esta é a era do empreendedorismo. Contextos sociopolíticos, culturais, de desenvolvimento tecnológico e o próprio fortalecimento capitalista, além de outros fatores, influenciaram conceitos administrativos no século XX, e, agora, acredita-se que o empreendedorismo está mudando esses conceitos, com uma nova forma de fazer negócios. (DORNELAS, 2018).

O empreendedorismo pode ser compreendido como a arte de fazer acontecer com criatividade e motivação, consistindo no prazer de realizar com sinergismo e inovação qualquer projeto pessoal ou organizacional, em desafio permanente às oportunidades e riscos, assumindo um comportamento proativo diante de questões que precisam ser resolvidas (BAGGIO; BAGGIO, 2015).

A criação de negócios envolve a figura central do empreendedor. O termo empreendedor tem origem na palavra francesa entrepreneur e quer dizer aquele que assume riscos e começa algo novo (DORNELAS, 2018). Os empreendedores são pessoas diferenciadas, que possuem motivação singular, apaixonadas pelo que fazem, não se contentam em ser mais um na multidão, querem ser reconhecidas e admiradas, referenciadas e imitadas, e desejam deixar um legado (DORNELAS, 2018).

O empreendedor segue o que acredita ser uma oportunidade, renova e inova em negócios já existentes em uma região, avalia o nível de incertezas em torno de uma oportunidade e a capacidade de agir contra tal incerteza (HISRICH, PETERS; SHEPHDERD, 2014). Os empreendedores estão renovando conceitos econômicos, eliminando barreiras comerciais e culturais, superando distâncias, gerando riquezas, derrubando paradigmas, inovam e renovam as relações de trabalho (DORNELAS, 2018).

Os empreendedores são considerados importantes para o desenvolvimento econômico. Para Baggio e Baggio (2015), os economistas percebem que o empreendedor é essencial ao processo de desenvolvimento econômico, pois em seus modelos estão levando em conta os sistemas de valores da sociedade e que são fundamentais os comportamentos individuais dos seus integrantes. De acordo com Hisrich, Peters \& Shephderd, (2014), o papel do empreendedorismo no desenvolvimento econômico envolve mais do que apenas o aumento de produção e renda per capita, adiciona-se o envolvimento em iniciar e constituir mudanças na estrutura do negócio e da sociedade.

O comportamento e processo empreendedor passa a ser um objeto de estudo. O processo empreendedor envolve todas as funções, atividades e ações associadas com a criação de novas 
empresas (HISRICH, PETERS; SHEPHDERD, 2014). As fases do processo empreendedor, apresentadas por Hisrich, Peters \& Shephderd, (2014) começam com a identificação e avaliação das oportunidades, em seguida desenvolve-se o plano de negócios, na fase seguinte determina e capta os recursos necessários e por fim, na última fase, gerencia a empresa criada.

Independentemente do papel que desempenhará no futuro, o empreendedor precisa entender o que os sistemas de informação podem fazer ou não fazer, e ser capaz de utilizá-los na realização do seu trabalho (STAIR; REYNOLDS, 2011).

\section{Sistemas de informação nos negócios}

A informação é um dos mais importantes patrimônios que qualquer organização tem à sua disposição, como qualquer outro ativo, precisa ser classificada, estruturada, validada, valorada, protegida, monitorada, medida e gerenciada eficiente e eficazmente (LAUDON; LAUDON, 2010). É possível que tudo que uma organização faça, envolva o uso da informação de algum modo. $O$ valor da informação é uma função do contexto da organização, da finalidade de utilização, do processo decisório e dos resultados das decisões (MORESI, 2000).

Enquanto as organizações mantêm suas operações em mercados globais cada vez mais competitivos, os trabalhadores de todas as áreas de negócios, como a contabilidade, finanças, recursos humanos, marketing e gerenciamento de operações e produção, precisam estar bem preparados (informados) para oferecer contribuições significativas, exigidas para o sucesso dos empreendimentos (STAIR; REYNOLDS, 2011).

A busca pela solução dos problemas conduz os gestores a unir as partes que compõem a organização para formar um sistema que dará condições para administrar o todo (BAZZOTTI; GARCIA, 2006). Para alcançar os objetivos organizacionais, os sistemas de informação são primordiais, pois possibilitam a criação de novos modelos de negócios, novos produtos e novos serviços (LAUDON; LAUDON, 2010).

A necessidade de implantar os sistemas de informação nas empresas surgiu devido ao grande e crescente volume de informações que a organização possui e pode propiciar uma visão das decisões, um diferencial em relação aos concorrentes, decisões mais rápidas e de fontes seguras. (BAZZOTTTI; GARCIA, 2006). Os sistemas de informação têm sido desenvolvidos para otimizar o fluxo de informação relevante no âmbito de uma organização, desencadeando um processo de conhecimento e de tomada de decisão e intervenção na realidade (.

Os sistemas de informação são conjuntos de componentes inter-relacionados que coletam, processam, armazenam, e distribuem informações que condicionam gerentes e empreendedores às tomadas de decisões, assim como permite coordenar e controlar uma empresa (LAUDON; LAUDON, 2010). As situações apontadas para tomadas de decisões podem ser sob condições de certeza, sob condições de incertezas e sob condições de risco (MARQUES, 2008). Uma das tarefas críticas de qualquer sistema de informação é a disponibilização da informação correta às pessoas certas e com oportunidade (MORESI, 2000).

Stair e Reynolds (2011) definem o sistema de informação como um conjunto de componentes interrelacionados que coleta (entrada), manipula (processamento), armazena e dissemina dados e informações (saída) e fornece um mecanismo de realimentação (retroalimentação) para atingir um objetivo.

O mecanismo de realimentação é o componente que ajuda as organizações a alcançar seus objetivos, como por exemplo, aumentar seus lucros ou melhorar seus serviços (STAIR; REYNOLDS, 2011). Ao descobrir as oportunidades de utilização dos sistemas de informação, espera-se que os sistemas de 
informação participem dos processos de solução dos problemas das organizações e seja empregado da melhor forma possível (STAIR; REYNOLDS, 2011).

Os sistemas de informação nos ambientes empresariais são constituídos do gerenciamento da informação, a partir do levantamento das necessidades informacionais dos decisores, da coleta e obtenção dos dados, na análise dos dados transformando-os em informação, na distribuição da informação de acordo com as necessidades do decisor, da utilização das informações pela sua incorporação no processo de trabalho e, finalmente, da avaliação constante dos resultados obtidos e de redirecionamentos no sistema para atender às demandas e antecipar as necessidades dos decisores (GUIMARÃES; ÉVORA, 2004).

As ferramentas da tecnologia da informação proporcionam vantagens substanciais para as organizações, como facilitar a tomada de decisões e monitorar os indicadores de desempenho (ANAYA, DULAIMI; ABDALLAH, 2015). A tecnologia da informação refere-se a hardware, software, banco de dados e telecomunicações. Uma Infraestrutura de Tecnologia de um negócio inclui todos os hardwares, softwares, bancos de dados, telecomunicações, pessoas e procedimentos que são configurados para coletar, manipular, armazenar e processar dados em informações (STAIR; REYNOLDS, 2011).

O conceito de alinhamento ou ajuste entre tecnologia da informação e estratégia de negócios tem sido discutido por muitos anos, e o alinhamento estratégico é considerado crucial para aumentar o desempenho da empresa (ISMAIL; KING, 2014). Para Anaya, Dulaimi e Abdallah (2015) a conscientização dos empreendedores sobre a importância da tecnologia da informação para análise de dados deve ser aumentada, porque quando esses empreendedores perceberem que podem aproveitar o crescente conjunto de dados consistentes e integrados na criação de novas iniciativas, eles fornecerão um forte suporte a tais iniciativas

A tecnologia de informação oferece recursos tecnológicos e computacionais para a geração de informações, e os sistemas de informação estão cada vez mais sofisticados, propondo mudanças nos processos, estrutura e estratégia de negócios (BAZZOTTI; GARCIA, 2006).

\section{Procedimentos metodológicos}

Esta pesquisa descritiva desenvolveu-se utilizando um questionário estruturado para coletar dados de empresas da cidade de Parauapebas, estado do Pará. A pesquisa teve uma abordagem quantitativa e a coleta de dados foi transversal. A pesquisa é divindade em duas etapas.

A primeira etapa foi pesquisa bibliográfica. Organizou-se a revisão de literatura sobre os temas empreendedorismo e sistemas de informação. Foram utilizados livros e artigos científicos como referências. Os artigos foram encontrados nas plataformas Google Acadêmico e Portal de Periódicos CAPES. Outra fonte utilizada foram sites de organizações públicas e privadas nacionais que divulgam dados referentes a cidade de Parauapebas.

A segunda etapa foi a pesquisa de campo. Um questionário estrutu rado foi elaborado e divide-se em duas partes. A primeira parte contém perguntas sobre as características das empresas e a segunda parte contém perguntas sobre o perfil de utilização dos sistemas de informação. Em seguida, o questionário passou por uma fase de testes com dois acadêmicos e três profissionais de administração. Após os ajustes, seguiu-se com a pesquisa de campo.

Foram convidadas 143 empresas e houve a participação de 60 empresas, dando uma aderência de $42 \%$ participação do total de empresas convidadas. A quantidade de empresas que responderam ao questionário equivale a 0,39\% do total das empresas abertas em Parauapebas. O critério de seleção das 
empresas foi ser uma empresa situada no município de Parauapebas. Não houve restrição para o ramo, tamanho e natureza das empresas. O método de seleção da amostragem foi a de amostras não probabilísticas por conveniência, pois as empresas foram visitadas pelos autores e convidadas para responder o questionário.

Participaram da pesquisa os representantes dos respectivos empreendimentos, da qual, garantiu-se o anonimato das empresas participantes. A coleta de dados foi realizada no período de 04 a 25 de junho de 2018. Os questionários foram aplicados por telefone e de maneira presencial nas empresas.

Os dados coletados foram inseridos nos softwares Microsoft Excel e IBM SPSS. Em seguida, iniciouse a descrição das características das empresas e a análise de cada questão separadamente e os seus respectivos resultados para possibilitar a elaboração das discussões dos resultados encontrados. Por fim, os resultados foram analisados de forma ampla para chegar na conclusão do trabalho.

\section{Apresentação e análise dos resultados}

\section{Características das empresas}

A pesquisa contou com a participação de 60 empreendedores do município de Parauapebas/PA. A primeira questão identificou o grau de escolaridade dos empreendedores, tendo como critério para os casos de sociedades empresariais, a consideração do proprietário com maior percentual de participação na empresa. A segunda questão identificou o tempo de existência das empresas. A Tabela 1, a seguir, apresenta um comparativo entre o grau de escolaridade dos entrevistados e o tempo de existência das empresas.

Tabela 1 - Grau de Escolaridade dos Empreendedores e Tempo de Existência das Empresas

\begin{tabular}{l|c|c|c|c|c}
\hline \multirow{2}{*}{ Escolaridade } & \multicolumn{3}{c|}{ Tempo de Existência da Empresa (anos) } & \multirow{2}{*}{ Total } \\
\cline { 2 - 6 } & $<\mathbf{1}$ & $\mathbf{1 ~ a ~ 4}$ & $\mathbf{4}$ a 7 & \multicolumn{7}{c}{$\mathbf{7}$} & \\
\hline Ensino Fundamental Completo & 0 & 0 & 1 & 0 & 1 \\
Ensino Médio Completo & 2 & 11 & 0 & 8 & 21 \\
Ensino Superior Incompleto & 1 & 5 & 0 & 11 & 8 \\
Ensino Superior Completo & 5 & 9 & 5 & 21 & 60 \\
\hline \multicolumn{1}{c|}{ Total } & 8 & 25 & 6 & & \\
\hline
\end{tabular}

A questão sobre o nível de escolaridade apresentou o maior resultado para a quantidade de entrevistados com nível superior completo, representando $50 \%$ do total de entrevistados. O nível médio completo foi representado por $35 \%$ dos entrevistados. Ao relacion ar com o tempo de existência das empresas, percebe-se que $41 \%$ das empresas possuem entre um a quatro anos de existência e $35 \%$ possuem acima de sete anos de existência.

Das empresas com mais de sete anos de existência, $52 \%$ das empresas são de proprietários com nível superior. Os negócios que possuem proprietários com maior grau de escolaridade podem apresentar maiores chances de continuidade, sobrevivência ou tempo de existência. Outro argumento que reforça a longevidade das empresas é quando os negócios são formados através da identificação de oportunidades ao invés de serem abertos por necessidades (Dornelas, 2018).

A terceira questão identificou os seguimentos das empresas. As categorias dos seguimentos das empresas foram classificadas em: (1) comércio: empresas que visam exclusivamente a venda ou comercialização de produtos, sem prestação de serviços; (2) serviços: empresas especializadas na prestação de serviços, sem atividades de venda de produtos; (3) comércio e serviços: empresas que realizam prestação serviços e comercializam produtos; (4) indústrias: empresas de manufaturas. 
A quarta questão identificou o porte das empresas conforme o seu faturamento anual, seguindo o enquadramento utilizado em 2018 pelo SEBRAE - Serviço Brasileiro de Apoio às Micro e Pequenas Empresas e pelo BNDES - Banco Nacional de Desenvolvimento Econômico e Social. As categorias foram classificadas em: (1) Microempreendedor Individual - MEI: até R \$ 81 mil; (2) Microempresas: até R\$360 mil; (3) Empresa de Pequeno Porte: de R\$ 360 mil até R\$ 4,8 milhões; (4) Empresa de Médio Porte: de R \$ 4,8 milhões até R \$300 milhões e (5) Empresa de Grande Porte: Acima de R \$300 milhões. A Tabela 2 apresenta um comparativo entre os resultados das questões 3 e 4.

Tabela 2 - Porte e Tipo das Empresas

\begin{tabular}{l|c|c|c|c|c}
\hline \multirow{2}{*}{\multicolumn{1}{c}{ Porte da Empresa }} & \multicolumn{3}{c|}{ Seguimento da Empresa } & \multirow{2}{*}{ Total } \\
\cline { 2 - 6 } & Comércio & Serviços & $\begin{array}{c}\text { Comércios e } \\
\text { Serviços }\end{array}$ & Indústria & 0 \\
\hline Microempreendedor Individual & 3 & 0 & 4 & 2 & 28 \\
Microempresas & 19 & 4 & 3 & 0 & 13 \\
Empresas de Pequeno Porte & 4 & 4 & 5 & 1 & 6 \\
Empresas de Médio Porte & 2 & 3 & 0 & 1 & 6 \\
Empresas de Grandes Porte & 2 & 2 & 1 & 4 & 60 \\
\hline \multicolumn{1}{c}{ Total } & 30 & 13 & 13 & & 4 \\
\hline
\end{tabular}

Fonte: Dados da pesquisa.

$\mathrm{Na}$ análise dos tipos de empresas, o seguimento de comércio apresentou a maior quantidade de empresas entrevistadas, representando $50 \%$ do total, seguido respectivamente pelo seguimento de serviços e de comércio e serviços com $22 \%$ do total cada um. Embora o setor industrial seja responsável por 66\% do PIB no município de Parauapebas (IBGE, 2015), o seguimento indústria representou apenas $6 \%$ das empresas entrevistadas.

Esses resultados podem contribuir para apontar que o setor industrial é bastante concentrado em poucas empresas na cidade. A presença da mineradora VALE S/A, maior multinacional brasileira do setor mineral e que apresentou lucro líquido de US \$ 1,6 bilhões no primeiro trimestre de 2018, tendo em Parauapebas algumas das suas maiores operações globais (VALE, 2018) reforça este argumento de elevada concentração do setor industrial e das atividades de mineração.

\section{Perfil de utilização dos sistemas de informação nos negócios}

A quantidade de empresas que assumem a utilização de Sistemas de Informação, indicando que 95\% fazem uso de algum tipo de sistema de informação. Identificou-se as versões utilizadas pelas empresas dos sistemas de informação, se são pagas ou gratuitas, e os resultados apontaram que $85 \%$ das empresas usam sistemas de informação pagos.

Verificou-se quais são as funções dos Sistemas de Informação que as empresas mais utilizam. Os resultados indicaram que $67 \%$ das empresas utilizam mais os sistemas de controle financeiro e contábil, que $67 \%$ utilizam os sistemas de controle de vendas e serviços, que $48 \%$ utilizam os sistemas de gerenciamento e relacionamento com clientes, que $48 \%$ utilizam sistemas de gestão de compras e $45 \%$ utilizam sistemas de gestão de estoque. A Tabela 3, a seguir, apresenta os resultados das funções dos sistemas de informação. 
Tabela 3 - Funções dos Sistemas de Informação

\begin{tabular}{lc}
\hline \multicolumn{1}{c}{ Funções dos Sistemas de Informação } & Quantidade de empresa \\
\hline Controle financeiro e contábil & 40 \\
Controle de vendas e serviços & 40 \\
Gerenciamento e relacionamento com clientes & 29 \\
Gestão de compras & 29 \\
Gestão de estoque & 27 \\
Gerenciamento e relacionamento com fornecedores & 18 \\
Gestão de documentos & 17 \\
Aplicativos para celulares & 17 \\
Marketing & 16 \\
Controle de indicadores & 16 \\
Apoio a tomada de decisão & 13 \\
Outras funções não especificadas & 11 \\
Gerenciamento de recursos humanos & 9 \\
\hline
\end{tabular}

Fonte: Dados da pesquisa.

Um aspecto que poderia prejudicar a implantação dos sistemas de informaçãoé o custo. Para $70 \%$ das empresas entrevistadas, os sistemas de informação são acessíveis financeiramente para serem implantados. As empresas responderam se tiveram consultoria para implantação de sistemas de informação. Os resultados apontaram que 38\% das empresas já contrataram consultorias para implantação de sistemas de informação.

As empresas responderam sobre o tempo de uso dos sistemas de informação. Para todas empresas de grande, médio e pequeno porte e microempresas, o sistema de informação é utilizado desde a implantação da empresa. A exceção ficou por conta de três microempreendedores individuais que não utilizam sistema de informação em seus negócios, portanto, não responderam esta questão. A Tabela 4, a seguir, apresenta o tempo de uso dos sistemas de informação e compara com o porte das empresas.

Tabela 4 - Tempo de Utilização dos Sistemas de Informação nos Negócios por Porte das Empresas

\begin{tabular}{|c|c|c|c|c|c|}
\hline \multirow[t]{2}{*}{ Porte da Empresa } & \multicolumn{4}{|c|}{$\begin{array}{c}\text { Tempo de Utilização dos Sistemas de Informação nos } \\
\text { Negócios (anos) }\end{array}$} & \multirow[t]{2}{*}{ Total } \\
\hline & $<1$ & 1 a 4 & 4 a 7 & $>7$ & \\
\hline $\begin{array}{l}\text { Microempreendedor Individual } \\
\text { Microempresas } \\
\text { Empresas de Pequeno Porte } \\
\text { Empresas de Médio Porte } \\
\text { Empresas de Grandes Porte }\end{array}$ & $\begin{array}{l}0 \\
6 \\
2 \\
0 \\
2\end{array}$ & $\begin{array}{c}4 \\
10 \\
8 \\
3 \\
1 \\
\end{array}$ & $\begin{array}{l}0 \\
7 \\
2 \\
1 \\
2\end{array}$ & $\begin{array}{l}0 \\
4 \\
2 \\
2 \\
1 \\
\end{array}$ & $\begin{array}{c}4 \\
27 \\
14 \\
6 \\
6 \\
\end{array}$ \\
\hline Total & 10 & 26 & 12 & 9 & 57 \\
\hline
\end{tabular}

Sobre a manutenção realizada em sistemas de informação, os resultados apontaram que 88\% das empresas realizam alguma manutenção, sendo $22 \%$ de forma apenas presencial nas empresas, $58 \%$ de forma apenas virtual e $20 \%$ de forma presencial e virtual. A forma pre sencialé definida neste trabalho pela presença física de técnicos especializados nas empresas. A forma virtual é a manutenção feita por internet ou telefone, sem a presença física de técnicos especializados dentro das empresas. 
As empresas responderam sobre a frequência da manutenção dos sistemas de informação. $O$ resultado indicou que 33\% das empresas não faz qualquer tipo de acompanhamento das manutenções. A Tabela 5 , a seguir, apresenta os resultados sobre a frequência de manutenção dos sistemas de informação.

Tabela 5 - Frequência de Manutenção dos Sistemas de Informação

\begin{tabular}{lcc}
\hline & Periodicidade & Total \\
\hline Pelo menos 1 vez ao mês & 17 \\
Pelo menos 1 vez a cada três meses & & 4 \\
Pelo menos 1 vez a cada seis meses & & 7 \\
Pelo menos 1 vez por ano & & 9 \\
Não faz o acompanhamento & Total & 20 \\
Não se aplica & Fonte: Dados da pesquisa. & 3 \\
\hline
\end{tabular}

Fonte: Dados da pesquisa.

Verificou-se onde estão localizadas as prestadoras de serviços responsáveis pelos sistemas de informação utilizados nas empresas entrevistadas. Os resultados apontaram que $30 \%$ dessas prestadoras de serviços tem representação em Parauapebas e $20 \%$ estão em localizadas outras cidades do estado do Pará. As empresas que possuem sede em outros estados representam $50 \%$ e estão em maior número. Estes resultados podem indicar que há poucas empresas especializadas em sistemas de informação na cidade de Parauapebas.

Sobre o treinamento dos usuários dos sistemas, para $83 \%$ das empresas todos os usuários são formalmente treinados, para $15 \%$ das empresas os usuários não são formalmente treinados e $2 \%$ responderam que são parcialmente treinados.

Para entender os tipos e grupos de registros, foram elaboradas três questões. Inicialmente, foram estabelecidos três grupos de registro, considerados importantes em todas as organizações e são eles: (1) Produtos e Serviços; (2) Fornecedores; (3) Clientes.

Os tipos de registros estabelecidos no questionário são: (1) Softwares Próprios, desenvolvidos exclusivamente para a empresa usuária; (2) Softwares Contratados / Licenciados, que são softwares de prateleira e que possuem características comuns para todos as empresas usuárias, sendo normalmente adquiridas licenças de uso temporárias; (3) Livros de Registros: são registros manuscritos em livros, cadernos de protocolos ou agendas; (4) Softwares Editor de Planilhas / MS Excel, são softwares tradicionais, que também possuem licença de uso, e são amplamente utilizados.

Os resultados para a questão sobre a principal forma de registros de produtos e serviços das empresas são: registros em software próprio com $15 \%$; registros em softwares contratados / licenciados com $60 \%$, registros em livros com $7 \%$ e registros em software editor de planilhas com $18 \%$.

Identificou-se a principal forma de registros dos fornecedores da empresa, os resultados são: registros em software próprio (15\%); registros em softwares contratados / licenciados (58\%), registros em livros $(5 \%)$ e registros em software editor de planilhas (22\%). Para a principal forma de registros dos clientes, os resultados são: registros em software próprio (15\%); registros em softwares contratados / licenciados (62\%), registros em livros (5\%) e registros em software editor de planilhas (18\%).

Os resultados indicaram que as empresas estão diminuindo os registros não eletrônico, como os usados em livros de registro em papel, sendo um sinal de que as tecnologias da informação estão substituindo os registros não digitais e manuscritos. A Tabela 6, a seguir, apresenta os resultados dos tipos de registro e grupo de registros. 
Tabela 6 - Tipos e Grupo de Registro

\begin{tabular}{l|c|c|c}
\hline \multicolumn{1}{c|}{ Tipo de Registro } & \multicolumn{2}{c}{ Grupo de Registro } \\
\cline { 2 - 4 } & Produtos e Serviços & Fornecedores & Clientes \\
\hline Software Próprio & 9 & 9 & 9 \\
Software Contratado / Licenciado & 36 & 35 & 37 \\
Livros de Registros / Papel & 4 & 3 & 3 \\
Software Editor de Planilhas / MS Excel & 11 & 13 & 11 \\
\hline \multicolumn{1}{c}{ Total } & 60 & 60 & 60 \\
\hline
\end{tabular}

Fonte: Dados da pesquisa.

As questões seguintes identificaram quais os meios de comunicação são utilizados pelas empresas entrevistadas para contato com fornecedores e clientes. O telefone é o principal meio de comunicação das empresas com fornecedores e com clientes, respectivamente apontado por $63 \%$ e $71 \%$ das empresas. Em seguida, aparecem como meio de comunicação com fornecedores e clientes as redes sociais com $41 \%$ e $63 \%$ respectivamente, os softwares de comunicação com fornecedores para $23 \%$ das empresas e com clientes para 58\% das empresas e outros meios de comunicação com uso de tecnologia da informação com fornecedores para $43 \%$ das empresas e com clientes para $30 \%$ das empresas.

Estes resultados podem indicar uma tendência de avanço na utilização de meios de comunicação mais atuais e baseados em tecnologia da informação, como as redes sociais e softwares de comunicação. A tabela 7 , a seguir, descreve a quantidade de empresas e os meios de comunicação utilizados com fornecedores e clientes.

Tabela 7 - Meios de Comunicação Utilizados pelas Empresas com Fornecedores e Clientes

\begin{tabular}{l|c|c}
\hline \multirow{2}{*}{ Meios de Comunicação } & \multicolumn{2}{c}{$\mathbf{N}^{\mathbf{0}}$ de incidência } \\
\cline { 2 - 3 } & Fornecedores & Clientes \\
\hline Software de Comunicação & 14 & 35 \\
Redes Sociais & 25 & 43 \\
Telefone & 38 & 0 \\
Videoconferência & 12 & 0 \\
E-mail & 6 & 18 \\
Outros Meios de Comunicação & 26 & 0 \\
Não se aplica & 1 & \\
\hline
\end{tabular}

Fonte: Dados da pesquisa.

Os empreendedores foram questionados sobre a importância dos sistemas de informação para a gestão dos negócios. Eles responderam por meio de uma escala de importância, podendo optar pelo nível mais baixo de importância, denominado pouco importante, em seguida elevando os níveis para razoavelmente importante, indiferente, importante e o mais elevado de todos os itens, denominado muito importante. Os resultados apontaram que $85 \%$ dos empreendedores entrevistados acreditam que ser muito importante os sistemas de informação para a gestão dos negócios.

\section{Considerações finais}

A utilização dos sistemas de informação nos negócios permite melhores oportunidades para a organização e pelo menos dois grupos internos são positivamente afetados: (1) Os usuários, que são beneficiados pelo melhor controle de processos, mais rapidez e qualidade, possibilitando executar suas 
tarefas com mais eficiência. (2) Os gerentes, que podem realizar o gerenciamento eficaz do negócio, utilizando os sistemas de informação para tomada de decisões em busca das metas estabelecidas e resultados esperados.

No cenário empresarial atual da cidade de Parauapebas, o sistema de informação tem contribuído para a melhoria da gestão dos negócios, desde os microempreendedores até as grandes empresas. Embora a cidade tenha elevada participação do setor industrial no PIB, principalmente devido as atividades de mineração, os demais setores da economia local também são relevantes no contexto econômico. $\mathrm{O}$ uso dos sistemas de informação nas organizações, independente do seu tamanho ou segmento, mostra importância em Parauapebas.

Entretanto, como os resultados da pesquisa apontaram, uma quantidade significativa de empresas locais precisa buscar apoio em outros estados para suprir as suas necessidades de implantação e manutenção dos sistemas de informação. Essa condição pode limitar o progresso das empresas na gestão dos negócios. Uma possibilidade é o aumento da oferta de prestadoras de serviços de sistema de informação devidamente capacitadas na cidade.

As empresas entrevistadas apontaram que a utilização dos sistemas de informação é importante para os seus negócios. Dessa maneira, percebe-se que o empreendedorismo moderno recebe valiosas contribuições da utilização dos sistemas de informação na gestão dos negócios.

A utilização de métodos de amostragem não probabilísticas é uma limitação da pesquisa. É possível que os resultados sejam restritos a amostra e apresentar características diferentes para a população de empresas da cidade, dessa maneira, os resultados devem ser generalizados. Outra limitação é a ausência de estudos anteriores na cidade que permitam uma comparação.

Como sugestão para pesquisas futuras, recomenda-se estudos separados por segmentos de mercados e tamanhos de empresas, a verificação de indicadores de performance na utilização dos sistemas de informação e a ampliação da base de empresas para análise.

\section{Referências}

ANAYA, Luay; DULAIMI, Mohammed; ABDALLAH, Sherief. An investigation into the role of enterprise information systems in enabling business innovation. Business Process Management Journal, v. 21, n. 4, p. 771-790, 2015.

BAGGIO, Adelar Francisco; BAGGIO, Daniel Knebel. Empreendedorismo: Conceitos e definições. Revista de empreendedorismo, inovação e tecnologia, v. 1, n. 1, p. 25-38, 2015.

BALTZAN, Paige; PHILLIPS, Amy. Sistemas de infor mação. AMGH Editora, 2012.

BANCO NACIONAL DE DESENVOLVIMENTO ECONÔMICO E SOCIAL Por te de empresa. Recuperado em 16 maio, 2018, de

https://www.bndes.gov.br/wps/portal/site/home/financiamento/guia/porte-de-empresa

BAZZOTTI, Cristiane; GARCIA, Elias. A importância do sistema de informação gerencial na gestão empresarial para tomada de decisões. Ciências Sociais Aplicadas em Revista, v. 6, n. 11, 2006.

BRASIL, MINISTÉRIO DA INDÚSTRIA, COMÉRCIO EXTERIOR E SERVIÇOS. Comex

Vis: Municípios. Acessado em 10 maio, 2018, de http://www.mdic.gov.br/comercioexterior/estatisticas-de-comercio-exterior/comex-vis/frame-municipio?municipio $=1505536$

DORNELAS, José Carlos Assis. Empreendedorismo: Transformando ideias em negócios $7^{\text {a }}$. Ed. Rio de Janeiro: Elsevier Brasil. 2018 
GLOBAL ENTREPEURSHIP MONITOR. Global Report. Acessado em 22 maio, 2018, de https://www.gemconsortium.org/report/50012

GUIMARÃES, Eliane Marina Palhares; ÉVORA, Yolanda Dora Martinez. Sistema de informação: instrumento para tomada de decisão no exercício da gerência. Ciência da informação, v. 33, n. 1, 2004.

HISRICH, Robert D.; PETERS, Michael P.; SHEPHERD, Dean A. Empreendedorismo. 9a . Ed. Porto Alegre: AMGH Editora, 2014.

INSTITUTO BRASILEIRO DE GEOGRAFIA E ESTATÍSTICA. Panorama estatístico do

Brasil. Acessado em 17, maio, 2018, de https://cidades.ibge.gov.br

INSTITUTO BRASILEIRO DE PLANEJAMENTO E TRIBUTAÇÃO. Estatísticas. Recuperado em 25 maio, 2018, de https://www.empresometro.com.br/Home/Estatisticas

ISMAIL, Noor Azizi; KING, Malcolm. Factors influencing the alignment of accounting information systems in small and medium sized Malaysian manufacturing firms. Jour nal of

Information Systems and Small Business, v. 1, n. 1-2, p. 1-20, 2014.

LAUDON, Kenneth; LAUDON, Jane. Sistemas de infor mação gerenciais. 9a . Ed. São Paulo: Pearson Prentice Hall, 2010.

MARQUES, Wagner Luiz. Diário de um empreendedor: A Real Informação para Gestores de Sucesso. Cianorte: Clube de Autores (managed), 2008.

MORESI, Eduardo Amadeu Dutra. Delineando o valor do sistema de informação de uma organização. Ciência da Informação, Brasília, v. 29, n. 1, p. 14-24, 2000.

STAIR, Ralph M.; REYNOLDS, George W. Princípios de Sistemas de Informação, 9ª Ed. São Paulo: Thomson, 2011.

SERVIÇO BRASILEIRO DE APOIO ÀS MICRO E PEQUENAS EMPRESAS. Lei geral das micro e pequenas empresas. Acessado em 10 maio, 2018, de http://www.sebrae.com.br/sites/PortalSebrae/sebraeaz/lei-geral-completa-10-anos-e-beneficiamilhoes-de-empresas, baebd455e8d08410VgnVCM2000003c74010aRCRD

TIMMONS, Jeffry A.; SPINELLI, Stephen. New venture creation: Entrepreneurship for the 21st century. New York: McGraw-Hill/Irwin, 2004.

VALE. Negócios. Acessado em 20 maio, 2018, de http://www.vale.com/brasil/PT/business/mining/iron-ore-pellets/Paginas/default.aspx 